\title{
Perancangan Lemari Buku Perpustakaan Bagi Penyandang Tunadaksa dan Tunanetra
}

\author{
Nofirza $^{1)}$, Anwardi, Keke Agnes Faulian ${ }^{2)^{\star}}$, Misra Hartati ${ }^{3)}$, Ismu Kusumanto ${ }^{4)}$ \\ 1,2,3,4) Jurusan Teknik Industri Universitas Islam Negeri Sultan Syarif Kasim Riau
}

Naskah diterima 04 Juli 2019; direvisi 22 September 2019; disetujui 28 Oktober 2019 doi: https://doi.org/10.24843/JEM.2019.v12.i02.p04

\begin{abstract}
Abstrak
Berdasarkan hasil data yang di peroleh dari SLB Negeri Pembina Pekanbaru jumlah penyandang tunadaksa dan tunanetra dari jenjang pendidikan sekolah dasar sampai sekolah menengah atas yaitu sebanyak 18 orang. Membaca merupakan salah satu sarana yang dapat dijadikan metode untuk mengasah kemandirian setiap penyandang disabilitas terutama penyandang tunadaksa dan tunanetra. Untuk itu sangat di perlukan sarana dan prasarana yang mendukung seperti lemari buku, buku bacaan, meja dan kursi. Namun, saat ini fasilitas yang tersedia belum memenuhi criteria yang sesuai dengan kondisi penyandang tunadaksa dan tunanetra sehingga perlu dilakukan kajian menggunakan Metode Kansei Engineering yang menerjemahkan perasaan pengguna ke dalam spesifikasi desain produk. Tujuan dilakukannya kajian ini untuk mempermudah penyandang tunadaksa dan tunanetra dalam menggunakan fasilitas perpustakaan terutama lemari. Hasil yang di peroleh dari penelitian ini yaitu untuk spesifikasi lemari tunadaksa adalah material triplek dengan warna cokelat tua, bentuk lemari yang simple, dan di berikan display yang besar untuk memudahkan pemilihan buku dengan ukuran yang di gunakan adalah tinggi duduk $47 \mathrm{~cm}$, tinggi mata duduk $36 \mathrm{~cm}$, dan tinggi kursi roda yaitu $37 \mathrm{~cm}$ dengan ukuran akhir produk yaitu tinggi meja $67 \mathrm{~cm}$ dengan sisi lemari $48 \mathrm{~cm}$. Sedangkan spesifikasi akhir lemari buku tunanetra adalah material triplek dengan warna cokelat tua, bentuk lemari yang simple, dan di berikan display berupa huruf Braille dengan ukuran tinggi lemari yaitu $117 \mathrm{~cm}$.

Kata Kunci: Kansei Engineering, Tunadaksa, Tunanetra
\end{abstract}

\begin{abstract}
Based on the results of data obtained from the Pembina Pekanbaru SLB, the number of phisical disability and visually impaired connections from the level of primary to high school education is 18 people. Reading is one of the tools that can make a method to hone the independence of each disability, especially for the phisical disability and visually impaired. For this reason, there is a great need for support and infrastructure that supports such as book cabinets, reading books, tables and chairs. However, at present the available facilities do not meet the criteria that are in accordance with the requirements of the disabled and the blind need to be assessed using the Kansei Engineering Method which translates the user's feelings into product design specifications. The purpose of this discussion is to allow phisical disability and visually impaired people to use special library facilities for cabinets. The results obtained from this study are for the specifications of the quadrilateral cupboard are plywood material with dark brown color, a simple cupboard shape, and a large display is provided to facilitate the selection of books with a size that is $47 \mathrm{~cm}$ high, $36 \mathrm{~cm}$ high, and wheelchair height is $37 \mathrm{~cm}$ with the final size of the product, which is a table height of $67 \mathrm{~cm}$ with a side cabinet of $48 \mathrm{~cm}$. While the final specifications of the blind bookshelf are plywood material with dark brown color, a simple cupboard shape, and played in the form of Braille letters with a cupboard height of $117 \mathrm{~cm}$.
\end{abstract}

Keywords: Kansei Engineering, Physical Disability, visual impaired

\section{Pendahuluan}

Membaca merupakan kegiatan yang dapat menambah wawasan dan pengetahuan serta dapat meningkatkan kualitas memori. Dengan membaca seseorang dapat mengaktualisasikan dirinya dengan informasi-informasi yang di dapat dari membaca buku. Semakin banyak buku yang dibaca maka semakin banyak informasi yang didapatkan. Salah satu fasilitas membaca di tempat umum adalah perpustakaan.

Menurut Kamus Besar Bahasa Indonesia (dikutip oleh salatoen, 2018), perpustakaan adalah tempat, gedung, ruang yang di sediakan untuk pemeliharaan dan penggunaan koleksi buku dan sebagainya. Sarana dan prasarana di dalam perpustakaan perlu di perhatikan agar pengguna perpustakaan merasa nyaman ketika menggunakannya. Perpustakaan biasanya terdapat di berbagai tempat seperti lembaga pendidikan, instansi maupun tempat pribadi.
SLB (Sekolah Luar Biasa) merupakan lembaga pendidikan khusus untuk anak berkelainan dan menampung anak berkelainan dengan jenis kelainan yang sama. Sedangkan SDLB menampung berbagai jenis anak berkelainan dalam satu atap, sehingga di dalamnya terdapat berbagai anak dengan kebutuhan khusus (Salatoen, 2018).

SLB Negeri Pembina Pekanbaru merupakan satu-satunya SLB Negeri yang ada di pekanbaru dengan tingkatan pendidikan mulai dari sekolah dasar sampai sekolah menengah atas. SLB Negeri Pembina menerima siswa dengan jenis cacat mulai dari tunarungu, tunagrahita, autis, tunadaksa dan tunanetra. Berikut data jumlah siswa yang ada di SLB Negeri Pembina Pekanbaru: 


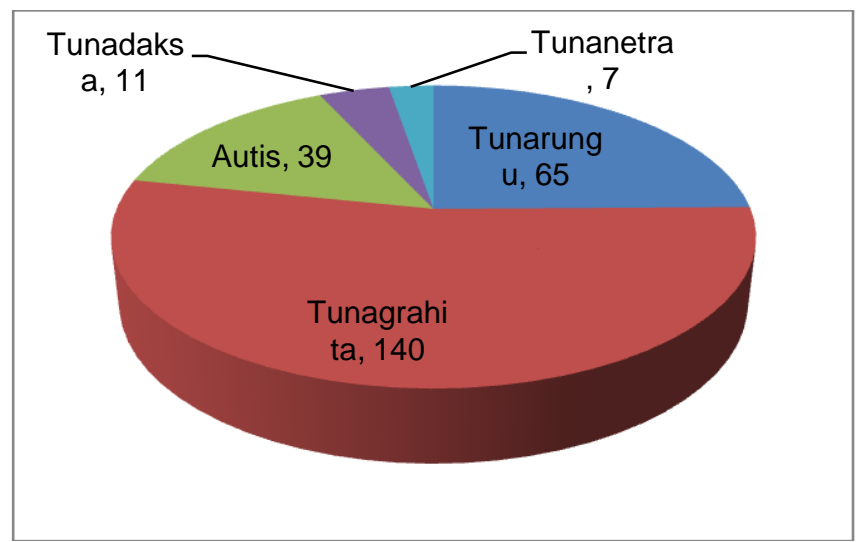

Gambar 1. Jumlah siswa SLB Negeri Pembina Pekanbaru

Permasalahan yang terjadi di sarana perpustakaan pada SLB Negeri Pembina Pekanbaru yaitu ketika terdapat penyandang tunadaksa yang ingin menjangkau buku yang di inginkan mereka kesulitan ketika ingin mengambil berbagai buku bacaan di lemari yang terdapat di perpustakaan. Mereka membutuhkan bantuan dari guru maupun orang tua ketika ingin mengambil buku yang di inginkan. Lemari buku yang terdapat di SLB Negeri Pembina belum user friendly bagi seluruh siswanya. Hal ini yang membuat kurangnya minat penyandang tunadaksa menggunakan fasilitas perpustakaan. Mereka juga harus menggunakan kursi roda jika ingin menjangkau buku yang lebih tinggi. Ketika ingin membaca buku, para penyandang tunadaksa meminta bantuan kepada guru dan teman yang lebih tinggi. Hal ini yang menyebabkan penyandang tunadaksa tidak memiliki kemandirian ketika menggunakan fasilitas umum seperti perpustakaan baik perpustakaan yang terdapat di sekolah khusus maupun perpustakaan yang terdapat di fasilitas umum lainnya.

Jika dibandingkan tinggi lemari dengan tinggi siswa penyandang tunadaksa memiliki rentang yang sangat jauh bagi siswa yang tidak memiliki bentuk tubuh normal. Sementara untuk siswa yang memiliki tubuh yang normal, mereka kesulitan ketika harus berdiri lama karena kaki mereka sangat lemah ketika untuk digunakan berdiri dalam waktu yang cukup lama. Hal ini membuat siswa penyandang tunadaksa membutuhkan bantuan guru maupun teman ketika ingin menjangkau buku yang diinginkan. Sementara, untuk lebar rata-rata buku bacaan yang terdapat di lemari tersebut adalah $12 \mathrm{~cm}$ dengan space jarak untuk menjangkau buku $26 \mathrm{~cm}$. Hal ini menyebabkan siswa menjangkau buku terlalu jauh dengan postur membungkuk dan dapat menyebabkan para siswa penyandang tunadaksa jatuh ketika akan membaca buku.

Selain itu tinggi rata-rata siswa dengan tinggi lemari untuk penyandang tunanetra memiliki jarak yang sangat jauh. Para siswa membutuhkan bantuan guru ketika ingin membaca buku yang di inginkan. Selain itu, tidak terdapat display khusus seperti huruf Braille sebagai penanda lemari dan buku bacaan pada sisi lemari khusus penyandang tunanetra. Hal ini menyebabkan siswa penyandang tunanetra tidak mandiri ketika ingin membaca buku bacaan yang di inginkan. Selain itu posisi dari lemari buku terlalu jauh dari pintu masuk yang akan menyebabkan kemungkinan penyandang tunanetra salah memilih lemari buku khusus penyandang tunanetra tersebut.

Melihat permasalahan yang terdapat di SLB

Negeri Pembina tersebut, peneliti akan merancang lemari buku yang ergonomis dan user friendly murid SLB Negeri Pembina khususnya bagi penyandang tunadaksa dan tunanetra dengan menggunakan metode kansei engineering. Kansei engineering adalah jenis teknologi yang menerjemahkan perasaan pelanggan ke dalam spesifikasi desain (Lokman, 2010 dikutip oleh Rahmayani, 2015). Dalam metode Kansei berdasarkan emotional pelanggan dan membutuhkan semua input sensory. Input sensory dalam tubuh sangat diperlukan guna mewakili emosi atau perasaan konsumen. Kebanyakan studi dalam pengembangan produk memanfaatkan metode rekayasa emosional, semua indera yang diperlukan digunakan (Nagamachi (2001) dalam Schutte (2002) dikutip oleh Rahmayani, 2015).

Menggunakan metode Kansei engineering diharapkan dapat menghasilkan lemari buku yang user friendly bagi penyandang tunadaksa dan tunanetra yang bisa menyelesaikan permasalahanpermasalahan sebelumnya pada SLB Negeri Pembina pekanbaru dan dapat menambah kemandirian siswa dalam penggunaan fasilitas perpustakaan.

\section{Metode Penelitian}

\subsection{Identifikasi Kansei Words}

Identifikasi kansei words dilakukan dengan cara wawancara langsung kepada murid tunadaksa dan tunanetra yang ada di SLB Negeri Pembina Pekanbaru. Setelah melakukan wawancara, hasil dari kansei words di perkuat dengan litetur yang ada. Setelah dilakukan wawancara untuk pengidentifikasian kansei words, selanjutnya dilakukan consult expert dengan seorang guru SLB. Tujuan pelaksanaan consult expert ini untuk menerjemahkan kansei words berdasarkan emosi dari murid SLB tersebut terhadap kebutuhan murid akan lemari buku yang tepat dan sesuai. Guru SIB di pilih sebagai consult expert dikarenakan guru tersebut yang mengerti akan kebutuhan murid sesungguhnya terhadap penggunaan rak buku. Berikut adalah kansei words yang didapatkan dari hasil wawancara dengan murid tunadaksa dan tunanetra serta consult expert pada Guru SLB yang ada di SLB Negeri Pembina Pekanbaru: 
Tabel 1 Struktur Kansei Words Penyandang Tunadaksa dan Tunanetra

\begin{tabular}{|c|c|c|c|}
\hline No & Primer & Sekunder & Kansei Words \\
\hline \multirow{4}{*}{1} & \multirow{4}{*}{$\begin{array}{c}\text { Material } \\
\text { Rak } \\
\text { Buku }\end{array}$} & Kayu & $\begin{array}{l}\text { 1. Tidak Mudah } \\
\text { Patah }\end{array}$ \\
\hline & & Triplek & 2. Ringan \\
\hline & & & 3. Bahan Aman \\
\hline & & Plastik & $\begin{array}{l}\text { 4. Tahan Lama } \\
\text { 5. Elastis }\end{array}$ \\
\hline \multirow{9}{*}{2} & \multirow{9}{*}{ Warna } & Merah & \multirow{7}{*}{ 6. Warna Terang } \\
\hline & & $\begin{array}{l}\text { Muda } \\
\text { (Pink) }\end{array}$ & \\
\hline & & Merah & \\
\hline & & Coklat & \\
\hline & & Tua & \\
\hline & & Biru & \\
\hline & & Kuning & \\
\hline & & Putih & \multirow[b]{2}{*}{ 7. Warna Soft } \\
\hline & & $\begin{array}{l}\text { Coklat } \\
\text { Muda }\end{array}$ & \\
\hline \multirow[b]{2}{*}{3} & \multirow[b]{2}{*}{ Desain } & \multirow{2}{*}{$\begin{array}{l}\text { Desain } \\
\text { Rak Buku }\end{array}$} & 8. Simple \\
\hline & & & $\begin{array}{l}\text { 9. Banyak motif } \\
\text { lucu }\end{array}$ \\
\hline 4 & Fitur & $\begin{array}{l}\text { Desain } \\
\text { Penanda }\end{array}$ & 10. Display Besar \\
\hline
\end{tabular}

\subsection{Pengujian validitas dan Reliabilitas}

Kansei words yang telah di identifikasi di terjemahkan dalam bentuk kuesioner dan di sebarkan ke siswa penyandang tunadaksa dan tunanetra di SIB Negeri pembina Pekanbaru. Kemudian dilakukan Pengujian validitas dan reliabilitas digunakan dari hasil kuesioner yang telah di sebarkan. Berikut adalah rumus pengujian validitas:

$r=\frac{N\left(\sum X Y\right)-\left(\sum X \sum Y\right)}{\sqrt{\left.\left\{N \sum X^{2}-\left(\sum X\right)^{2}\right)\right\}\left\{N \sum Y^{2}-\left(\sum Y\right)^{2}\right)}}$

Dimana:

$r \quad=$ Angka Korelasi

$\mathrm{N}=$ Jumlah sampel

$\mathrm{X}=$ Skor Item Pertanyaan

$\mathrm{Y}=$ Skor Total item pertanyaan

Berikut adalah rumus pengujian reliabilitas terhadap kuesioner yang telah di sebarkan:

$R_{X Y}=\left[\frac{k}{k-1}\right]\left[1-\frac{\sum \sigma^{2} b}{\sigma^{2} t}\right]$

Dimana:

$R_{X Y}=$ Mean kuadrat antara subyek

$\sum \sigma^{2} \mathrm{~b}=$ Mean Kuadrat Kesalahan

$\sigma^{2} \mathrm{t}=$ Varians total

\subsection{Analisis Faktor}

Analisis faktor merupakan salah satu metode multivariate yang digunakan untuk menganalisis variabel-variabel yang di duga memiliki keterkaitan satu sama lain sehingga keterkaitan tersebut dapat di jelaskan dan dipetakan atau di kelompokkan pada variabel yang tepat.

\subsubsection{Pengujian Barlet}

Uji barlett digunakan untuk mengetahui apakah terdapat hubungan antara variabel satu dengan lainnya. Jika dalam uji barlett ditemukan bahwa variabel satu dengan variabel lainnya tidak berkorelasi, maka analisis faktor tidak dapat di lakukan.

\subsubsection{MSA (Measure of Sampling Adquacy)}

MSA digunakan untuk mengukur seberapa tepat variabel terpredisksi oleh variabel lainnya dengan tingkat error yang relatif kecil atau dengan kata lain MSA berfungsi untuk mengukur validitas dari atribut. Berdasarkan nilai MsA dapat ditarik kesimpulan bahwa:

1. $M S A=1$ berarti variabel dapat di prediksi secara tepat tanpa kesalahan atau erorr

2. MSA $>0,5$, variabel masih bisa di prediksi oleh variabel lain

3. $M S A<0,5$, variabel tidak di prediksi dan harus di keluarkan dari analisa faktor.

\subsection{Analisis Konjoin}

Analisis konjoin digunakan untuk mengetahui hubungan antara elemen desain rak buku dengan kansei words berdasarkan hasil kuesioner SD 2. Dalam analisa konjoin perlu di tentukan sampel minimum dengan jumlah kategori item sehingga akan di dapatkan sampel minimum yang di butuhkan.

\subsection{Konsep Desain dan Spesifikasi}

Dalam pembuatan konsep desain, peneliti menggunakan beberapa data antropometri siswa SLB Negeri Pembina Pekanbaru khususnya penyandang tunadaksa dan tunanetra. Data antropometri merupakan data dimensi-dimensi pada tubuh manusia.

\section{Hasil dan Pembahasan}

\subsection{Pengujian Validitas dan Reliabilitas}

Kansei words yang telah teridentifikasi diterjemahkan kedalam kuesioner semantic differential 1 dan disebarkan ke 18 siswa penyandang tunadaksa dan tunantetra di SLB negeri Pembina Pekanbaru. Dari 10 pernyataan diketahui semua pernyataan bernilai valid dan cronbac's alfa bernilai 0,905 yang termasuk dalam kategori reliabilitas sangat tinggi.

\subsection{Analisis Faktor}

Pengujian kelayakan analisis faktor di lakukan dengan menggunakan Kaiser mayer olkin dan barlett's test sphericity. Dalam pengujian ini bertujuan untuk mengetahui apakah data hasil uji validitas dan uji reliabilitas data yang dikumpulkan dari pernyataan responden dapat dilakukan analisis faktor atau belum. Berikut adalah nilai analisis faktor pada iterasi pertama:

Tabel 2 Hasil Pengujian KMO and Barlett's Test Iterasi-1

\begin{tabular}{l|l|c}
\hline KMO and Barlett's Test \\
\hline $\begin{array}{l}\text { Kaiser-Mayer_Olkin Measure of } \\
\text { Sampling Adequaci }\end{array}$ & 0,680 \\
\hline $\begin{array}{l}\text { Barlett's Test of } \\
\text { Shericity }\end{array}$ & $\begin{array}{l}\text { Approx. Chi- } \\
\text { Square }\end{array}$ & 129,780 \\
\hline & Df & 45 \\
\hline & Sig & 0,000 \\
\hline
\end{tabular}


Berikut adalah hasil pemeriksaan pada nilai MSA pengolahan uji kelayakan analisis faktor:

Tabel 3 Rekapitulasi Hasil MSA Iterasi-1

\begin{tabular}{lll}
\hline No & Kansei Word & Nilai MSA \\
\hline 1 & Material Tidak Mudah Patah & 0,818 \\
\hline 2 & Material Ringan & 0,805 \\
\hline 3 & Material Aman & 0,795 \\
\hline 4 & Material Tahan Lama & 0,705 \\
\hline 5 & Material Elastis & 0,512 \\
\hline 6 & Warna Lemari Terang & $\mathbf{0 , 4 9 7}$ \\
\hline 7 & Warna Lemari Soft & 0,619 \\
\hline 8 & Bentuk Lemari Simple & 0,644 \\
\hline 9 & $\begin{array}{l}\text { Lemari Di lengkapi Motif } \\
\text { Lucu }\end{array}$ & 0,628 \\
\hline 10 & $\begin{array}{l}\text { Terdapat Display yang } \\
\text { Besar }\end{array}$ & 0,810 \\
\hline
\end{tabular}

Berdasarkan rekapitulasi nilai MSA di atas, dapat di lihat bahwa kansei words ke-5 nilai $M S A<0,5$ sehingga perlu dilakukan eliminasi MSA ke-6 karena pernyataan ke-6 tersebut tidak dapat memprediksi variabel lainnya dan perlu dilakukan pengujian analisis faktor iterasi ke-2.

Berikut adalah hasil pengolahan uji kelayakan analisis faktor iterasi ke-2:

Tabel 4 Hasil Pengujian KMO and Barlett's Test iterasi ke-2

\begin{tabular}{l|l|c}
\hline KMO and Barlett's Test \\
\hline $\begin{array}{l}\text { Kaiser-Mayer_Olkin Measure of } \\
\text { Sampling Adequaci }\end{array}$ & 0,827 \\
\hline $\begin{array}{l}\text { Barlett's Test of } \\
\text { Shericity }\end{array}$ & $\begin{array}{l}\text { Approx. Chi- } \\
\text { Square }\end{array}$ & 109,318 \\
\hline & Df & 36 \\
\hline & Sig & 0,000 \\
\hline
\end{tabular}

Berikut adalah hasil pemeriksaan pada nilai MSA pengolahan uji kelayakan analisis faktor:

Tabel 5 Rekapitulasi Hasil MSA iterasi ke-2

\begin{tabular}{lll}
\hline No & Kansei Word & Nilai MSA \\
\hline 1 & Material Tidak Mudah Patah & 0,730 \\
\hline 2 & Material Ringan & 0,808 \\
\hline 3 & Material Aman & 0,858 \\
\hline 4 & Material Tahan Lama & 0,823 \\
\hline 5 & Material Elastis & 0,851 \\
\hline 7 & Warna Lemari Soft & 0,849 \\
\hline 8 & Lentuk Lemari Di lengkapi Motif Lucu & 0,921 \\
\hline 9 & Terdapat Display yang Besar & 0,764 \\
\hline
\end{tabular}

Berdasarkan hasil pengujian analisis faktor iterasi ke-2 diketahui bahwa nilai MSA>0,5 hal ini dapat dikatakan bahwa seluruh kansei words dapat memprediksi variabel lainnya dan layak untuk dilakukan analisis faktor lebih lanjut.

\subsection{Analisis Konjoin}

Sebelum dilakukan analisis konjoin, perlu dilakukan pembentukan stimuli elemen desain lemari buku bagi penyandang tunadaksa dan tunanetra sebelumnya, maka dilakukan penyebaran kuesioner evaluasi tingkat kepentingan terhadap responden yang berjumlah 11 orang penyandang tunadaksa dan 7 orang penyandang tunanetra. Berikut adalah hasil rekapitulasi analisis konjoin penyandang tunadaksa dan tunanetra:

Tabel 6 Nilai Kegunaan (Utilitas) Tiap Atribut Lemari Tunadaksa

\begin{tabular}{|c|c|c|c|c|c|}
\hline $\begin{array}{l}N \\
0\end{array}$ & $\begin{array}{c}\text { Elem } \\
\text { en }\end{array}$ & Kategori & $\begin{array}{c}\text { Rata- } \\
\text { Rata } \\
\text { Rankin } \\
\text { g }\end{array}$ & $\begin{array}{c}\text { Devia } \\
\text { si }\end{array}$ & $\begin{array}{c}\text { Kegunaa } \\
n \\
\text { (Utilitas) }\end{array}$ \\
\hline \multirow{3}{*}{1} & \multirow{3}{*}{$\begin{array}{l}\text { Mate } \\
\text { rial } \\
\text { Fisik }\end{array}$} & Kayu & 6,5 & 2 & -2 \\
\hline & & Triplek & 1,5 & -3 & 3 \\
\hline & & Plastik & 3 & $-1,5$ & 1,5 \\
\hline \multirow{2}{*}{2} & \multirow{2}{*}{$\begin{array}{c}\text { War } \\
\text { na }\end{array}$} & $\begin{array}{l}\text { Coklat } \\
\text { Tua }\end{array}$ & 4 & $-0,5$ & 0,5 \\
\hline & & $\begin{array}{l}\text { Coklat } \\
\text { Muda }\end{array}$ & 5 & 0,5 & $-0,5$ \\
\hline \multirow[b]{2}{*}{3} & \multirow{2}{*}{$\begin{array}{l}\text { Desa } \\
\text { in } \\
\text { Lem } \\
\text { ari }\end{array}$} & Simple & 3,75 & $-0,75$ & 0,75 \\
\hline & & Rumit & 5,25 & 0,75 & $-0,75$ \\
\hline \multirow{2}{*}{4} & \multirow{2}{*}{ Motif } & $\begin{array}{l}\text { Display } \\
\text { Besar }\end{array}$ & 4,25 & $-0,25$ & 0,25 \\
\hline & & $\begin{array}{l}\text { Display } \\
\text { Kecil }\end{array}$ & 4,75 & 0,25 & $-0,25$ \\
\hline
\end{tabular}

Tabel 7 Nilai Kegunaan (Utilitas) Tiap Atribut Lemari Tunanetra

\begin{tabular}{|c|c|c|c|c|c|}
\hline $\begin{array}{l}N \\
0\end{array}$ & $\begin{array}{c}\text { Eleme } \\
n\end{array}$ & $\begin{array}{c}\text { Katego } \\
\text { ri }\end{array}$ & $\begin{array}{l}\text { Rata- } \\
\text { Rata } \\
\text { Rankin } \\
\text { g }\end{array}$ & $\begin{array}{c}\text { Devia } \\
\text { si }\end{array}$ & $\begin{array}{c}\text { Kegunaa } \\
n \\
\text { (Utilitas) }\end{array}$ \\
\hline \multirow{3}{*}{1} & \multirow{3}{*}{$\begin{array}{l}\text { Materi } \\
\text { al Fisik }\end{array}$} & Kayu & 5.75 & 1.25 & -1.25 \\
\hline & & Triplek & 2 & -2.5 & 2.5 \\
\hline & & Plastik & 4.5 & 0 & 0 \\
\hline \multirow{2}{*}{2} & \multirow{2}{*}{ Warna } & $\begin{array}{l}\text { Cokela } \\
\text { t Tua }\end{array}$ & 4.25 & -0.25 & 0.25 \\
\hline & & $\begin{array}{l}\text { Cokelat } \\
\text { Muda }\end{array}$ & 5.75 & 1.25 & -1.25 \\
\hline \multirow{2}{*}{3} & \multirow{2}{*}{$\begin{array}{l}\text { Desain } \\
\text { Lemari }\end{array}$} & Rumit & 5 & 0.5 & -0.5 \\
\hline & & Simple & 4 & -0.5 & 0.5 \\
\hline \multirow{2}{*}{4} & \multirow{2}{*}{ Motif } & $\begin{array}{l}\text { Display } \\
\text { Besar }\end{array}$ & 5.75 & 1.25 & -1.25 \\
\hline & & $\begin{array}{l}\text { Displa } \\
\text { y Kecil }\end{array}$ & 3.25 & -1.25 & 1.25 \\
\hline
\end{tabular}

\subsection{Konse Desain dan Sesifikasi}

Berdasarkan data antropometri yang telah dikumpulkan oleh peneliti, maka peneliti memutuskan dan mempertimbangkan untuk menggunakan nilai ekstrim bawah agar memudahkan pengguna yang memiliki tinggi terendah ketika ingin menjangkau buku di lemari buku yang telah di rancang. Berikut adalah rekapitulasi penggunaan data antropometri pada perancangan lemari buku penyandang tunadaksa:

Tabel 8 Rekapitulasi Data Antropometri Penyandang Tunadaksa

\begin{tabular}{ll}
\hline Tinggi Duduk & 47 \\
\hline Tinggi Mata Duduk & 36 \\
\hline Tinggi Kursi Roda & 37 \\
\hline
\end{tabular}


Berikut adalah hasil rancangan lemari buku Tunadaksa dan spesifikasi produknya:

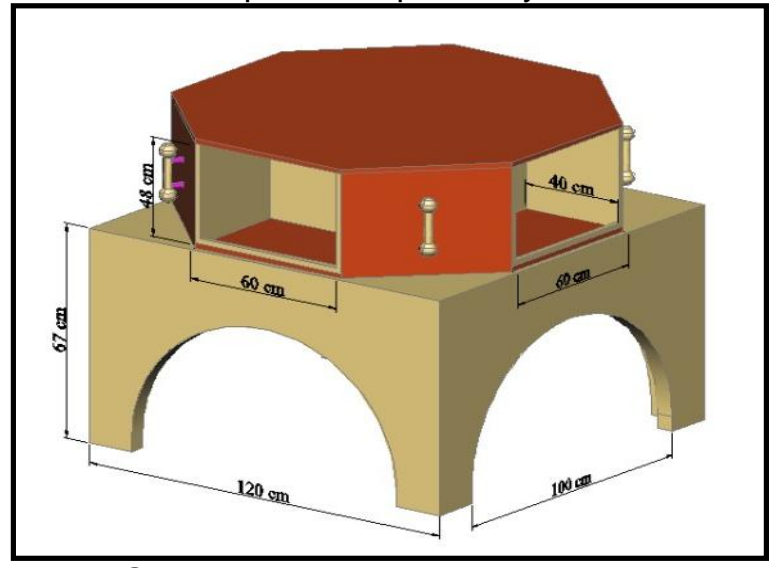

Gambar 2 Lemari Buku Tunadaksa

Adapun display yang akan di letakkan pada setiap sisi lemari buku adalah sebagai berikut:

1. Buku IImu Pengetahuan yang berisikan semua buku-buku pelajaran yang digunakan pada saat proses pembelajaran di kelas.

2. Buku Agama berisikan semua buku tentang ilmu agama, baik kitab suci maupun buku lainnya yang berkaitan dengan ilmu agama.

3. Buku Cerita, sisi lemari ini berisikan buku-buku yang berisi cerita baik cerita rakyat, cerita nabi dan lain-lain

4. Buku Lainnya, sisi lemari ini berisikan buku-buku yang banyak digunakan pada ekstrakurikuler di SLB Negeri Pembina Pekanbaru, seperti buku resep makanan, buku cara membatik, buku puisi, dan lain-lainnya.

Sedangkan untuk penyandang tunanetra peneliti menggunakan nilai extrime bawah dari tinggi berdiri siswa penyandang tunanetra yaitu $117 \mathrm{~cm}$. berikut adalah hasil rancangan lemari buku untuk penyandang tunanetra:

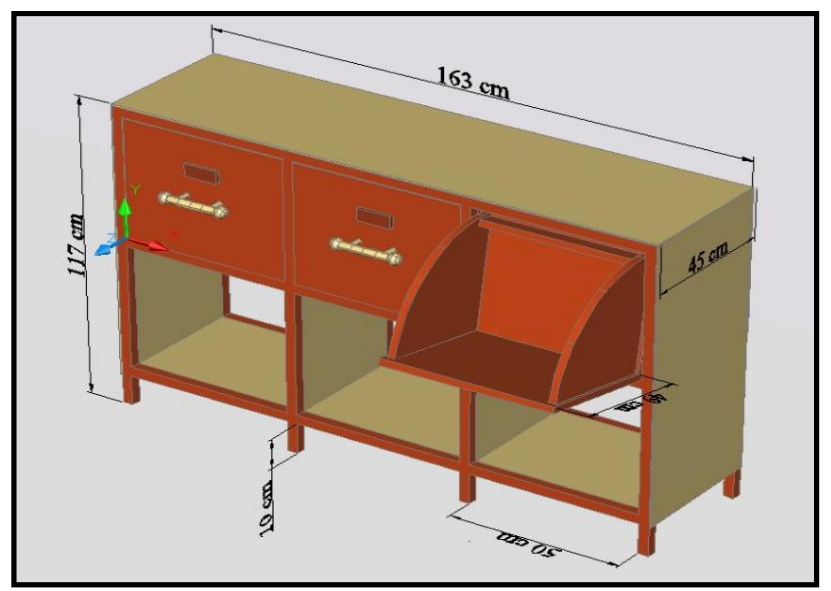

Gambar 3 Lemari Buku Tunanetra

Lemari buku tunanetra juga di lengkapi display yang berguna untuk membedakan antara peletakan buku satu dengan lainnya. Display yang digunakan pada lemari ini berupa huruf Braille. Hal ini dikarenakan siswa tunanetra menggunakan huruf Braille sebagai media membacanya. Adapun display yang digunakan untuk membedakan antara 1 sisi lemari dengan bagian lainnya adalah sebagai berikut::
Tabel 9 Display (Huruf Braille) yang digunakan pada pembuatan lemari buku tunanetra

\begin{tabular}{|c|c|c|}
\hline No & $\begin{array}{c}\text { Display yang } \\
\text { digunakan }\end{array}$ & $\begin{array}{c}\text { Display yang digunakan } \\
\text { (Dalam Huruf Braille) }\end{array}$ \\
\hline \multirow{3}{*}{1} & \multirow{3}{*}{ Ilmu Pengetahuan } & $\begin{array}{llll}\ldots & \ldots & \ldots & \ldots \\
. & \ldots & & \end{array}$ \\
\hline & & 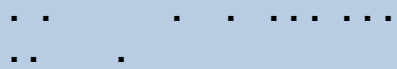 \\
\hline & & $\begin{array}{ll}\cdots & \cdot \\
\ldots & \end{array}$ \\
\hline \multirow{3}{*}{2} & \multirow{3}{*}{ Agama } & $\ldots \ldots$ \\
\hline & & $\ldots$ \\
\hline & & $\cdot$ \\
\hline \multirow{3}{*}{3} & \multirow{3}{*}{ Cerita } & $\ldots \cdot \ldots$ \\
\hline & & $\ldots$. \\
\hline & & $\cdot$ \\
\hline
\end{tabular}

\section{Simpulan}

Kesimpulan dari penelitian ini yaitu, untuk merancang ulang lemari buku tunadaksa berdasarkan orientasi perasaan konsumen dengan menggunakan metode kansei engineering berdasarkan elemen desain terpilih adalah sebagai berikut:

Tabel 10 Dimensi Hasil Rancangan Lemari Buku Tunadaksa

\begin{tabular}{llll}
\hline No & Komponen & Dasar Ukuran & Dimensi \\
\hline 1 & Meja & $\begin{array}{l}\text { Tinggi Kursi roda } \\
\text { dan } 1 / 2 \text { tinggi } \\
\text { mata duduk }\end{array}$ & \\
\hline 2 & $\begin{array}{l}\text { Sisi } \\
\text { Lemari }\end{array}$ & Tinggi Buku & $48 \mathrm{~cm}$ \\
\hline
\end{tabular}

Sedangkan lemari buku tunanetra menggunakan elemen desain sebagai berikut:

Tabel 11 Dimensi Hasil Rancangan Lemari Buku Tunanetra

\begin{tabular}{llll}
\hline No & Komponen & Dasar Ukuran & Dimensi \\
\hline 1 & Tinggi & Tinggi Siswa & $117 \mathrm{~cm}$ \\
& Lemari & Extrime Rendah & \\
\hline 2 & $\begin{array}{l}\text { Sisi } \\
\text { Lemari }\end{array}$ & Tinggi Buku & $45 \mathrm{~cm}$ \\
\end{tabular}

\section{Daftar Pustaka}

[1] Salatoen, C. B. T., Mas, D. A., Della, T. L., dan Sari, A. D., Desilisius (Desain Lemari Buku Siklus) Inovasi Lemari Buku Perpustakaan User Frendly Bagi Penyandang Tunadaksa, Seminar Nasional IENACO, Universitas Islam Indonesia, 2018.

[2] Rahmayani, N., Yuniar, Desrianty, A., Rancangan Kemasan Bedak Tabur (Loose Powder) Dengan menggunakan Metode Kansei Engineering, Jurnal Online Institut Teknologi Nasional, Vol.03 No.04, 2015.

[3] Wahyuning, C.S., Desrianty, A., dan Rahmawati, R., Studi Rancangan Konsep Brassiere melalui Pendekatan Nilai Emosi dan dan Perasaan Menggunakan Kansei Engineering Method, Jurnal Itenas Rekarupa. Vol. 1, No. 1, 2011, pp. 56-69.

[4] Ady, W. A. G., Pengembangan Desain Kursi Roda Khususnya Pada Lansia Berdasarkan Citra (Image) Produk Dengan Metode Kansei Engineering, Tugas Akhir, Jurusan Teknik 
Industri, Universitas Sebelas Maret, Surakarta,

2011.

[5] Usman, Hardius dan Sobari, N., Aplikasi Teknik Multivariate, PT. Raja Grafindo Persada, Jakarta, 2013.

[6] Thesman, O. G., dan Rahardjo, J., Pengembangan Produk Masker di PT.XYZ Dengan Menggunakan Metode Kansei Engineering, Jurnal Titra, Vol. 5, No.1, 2017, pp. 31-38. 